\title{
Characterisation of South African Chromite Middle Group Seams
}

\author{
Mashudu Maruli, Willie Nheta \\ University of Johannesburg \\ P.O.BOX 17011, Doornfontein 2028, Johannesburg, South Africa \\ Mmaruli30@gmail.com; wnheta@uj.ac.za
}

\begin{abstract}
In this paper, detailed physical and chemical characterisation of the South African chromite Middle group seams (MG 1, 2, 3 and 4) was conducted to determine the effect it has in choosing the type of milling equipment and establish how the mineralogical characteristics vary in order to decide whether they should be processed separately or blended together. The chemical composition was analysed using XRF, mineralogical phases determined using XRD and elemental analysis as well as grain particle sizes were obtained from SEM and EDS. XRF results showed that the $\mathrm{Cr}_{2} \mathrm{O}_{3}$ content in all seams was between 30 and $35 \%$ by weight and mostly associated with $\mathrm{Fe}, \mathrm{Si}, \mathrm{Mg}$, and $\mathrm{Al}$ elements. Most dominant phases are that of chromite and magnetite in all the samples. The amount of chromium element by $\%$ weight in all seams ranged between $20 \%$ to $28 \%$ as obtained from the EDS. The particle size of the grains in the ore ranged between 20 to $420 \mu \mathrm{m}$, with majority being between 150 and $200 \mu \mathrm{m}$. SEM showed that minerals were well distributed within the ore, with very few that were clustered together. From above mentioned mineralogical analysis that has been conducted thus far it was observed that all Middle group seams showed very similar characteristics, and blending them for processing would be most recommended, however they can also be processed separately depending on the availability of the ore.
\end{abstract}

Keywords: Chromite, Middle Group seam, Mineralogy, Processing, Grinding, Comminution

\section{Introduction}

Chromite is a very important mineral because it is the only economical viable source of chromium. South African chromite occurs within the Bushveld Igneous Complex (BIC) and is considered as stratiform chromite [1]. The BIC holds three quarters of the world's viable chromite ore deposits [2], and has an aerial extent of $65000 \mathrm{~km}^{2}$ with thickness of about 7 to $8 \mathrm{~km} \mathrm{[3].} \mathrm{The} \mathrm{BIC} \mathrm{consist} \mathrm{of} \mathrm{western,} \mathrm{eastern} \mathrm{and} \mathrm{the} \mathrm{northern} \mathrm{limbs.} \mathrm{Various} \mathrm{chromite} \mathrm{seams} \mathrm{occur} \mathrm{within} \mathrm{the}$ BIC and, the thickness of these seams ranges between 0.4 to $2.5 \mathrm{~m}$ [4]. Previous studies indicated that only three seams are currently considered to be economically viable and these are the LG6 (Lower Group), MG1(Middle Group) and the UG2 (Upper Group) consecutively [5].The LG6 and MG1 are exploited specifically for chromite not PGE's whilst UG2 is primarily exploited for PGEs and chromite as a by-product [6]. Middle group seam consist of 4 layers namely MG1, MG2, MG3 and MG4, and they vary in thickness ranging from 1.1 to $1.8 \mathrm{~m}$ with the MG1 having thickness ranging from 1.6 to $1.8 \mathrm{~m}$ and considered most economical viable to exploit amongst the 4 layers of the Middle group [5]. The LG6 thickness ranges from 1.1 to $1.3 \mathrm{~m}$ [5]. The chromite content of the LG6 seam is higher than that of the MG1 seam and it ranges between 43 to $47 \% \mathrm{Cr}_{2} \mathrm{O}_{3}$ compared to the $42 \% \mathrm{Cr}_{2} \mathrm{O}_{3}$ of the MG1 seam and $43.5 \%$ of UG2.

Although various studies indicated that only three seams are economically viable to exploit as mentioned above, some mines are already exploiting other chromite layers within the Middle group, and these are the MG2, 3 and 4 [6]. This might be due to depreciation of high-grade chromite seams. Chromite processing involves crushing, milling to less than $1 \mathrm{~mm}$ and further beneficiation using gravity circuits and spiral concentrators are widely used for this purpose.

In this study, characterisation on all the Middle group seams ore obtained from western limb was conducted in order to investigate how comparable they are from each other with an aim of determining whether the seams should be blended during processing or should be treated individually as they are being exploited. The second aim was also to see how the minerals occur within the ore and determine how the mineralogical characteristics will affect the choice of grinding equipment to be used for better grinding efficiency which is very critical for chromite recovery downstream. 


\section{Methodology}

\subsection{Characterisation}

Chromite sample was obtained from the western limb of the BIC along the Middle group seam. The samples were from MG1, MG2, MG3 and MG4. Particle size distribution on the as received samples were analysed using laboratory sieve screens. $1 \mathrm{~kg}$ from each sample was pulverised to $80 \%-75 \mu \mathrm{m}$ in preparation for chemical and mineralogical analysis. $20 \mathrm{~g}$ from each seam was scooped and blended together to produce a blend sample of the seams. Five samples (MG1, MG2, MG3, MG4 and a blend) in total were characterised.

Chemical composition on the samples were identified using a Rigaku ZSX Primus II -X-Ray Fluorescence (XRF) machine. The mineralogical phases were identified using the Rigaku Ultima X-ray diffraction (XRD) with $\mathrm{Cu} \mathrm{Ka}$ radiation. The morphology of the chromite ore in the samples was analysed using TESCA scanning electron microscope (SEM). Chemical composition analysis and particle sizes of grains in the sample were analysed using EDS.

\section{Results and Discussion}

\subsection{Particle Size Distribution}

Figure 1 show particle size distribution of all samples (MG 1-4) as received. Samples were neither crushed nor milled but straight from the pit. From Figure 1, it can be seen that the particle size distribution of all middle group seam layers are very similar. All the samples had some natural occurring fines as produced during blasting process. Particles that are less than $1000 \mu \mathrm{m}$ are not milled during chromite processing, they are directly sent to the beneficiation plant [7].

This is mainly because sending such particle to milling will results in ultrafine creation which is not good for chromite recovery downstream. Adequate pre-screening of the ore is critical to ensure that all fine particle are removed prior to milling [7]. It can also be seen from Figure 1 that majority of the particles in both middle group seam layer are of course fraction ranging from 1000 to $100000 \mu \mathrm{m}$, hence crushing or grinding of such particles is necessary for processing downstream during chromite recovery [8].

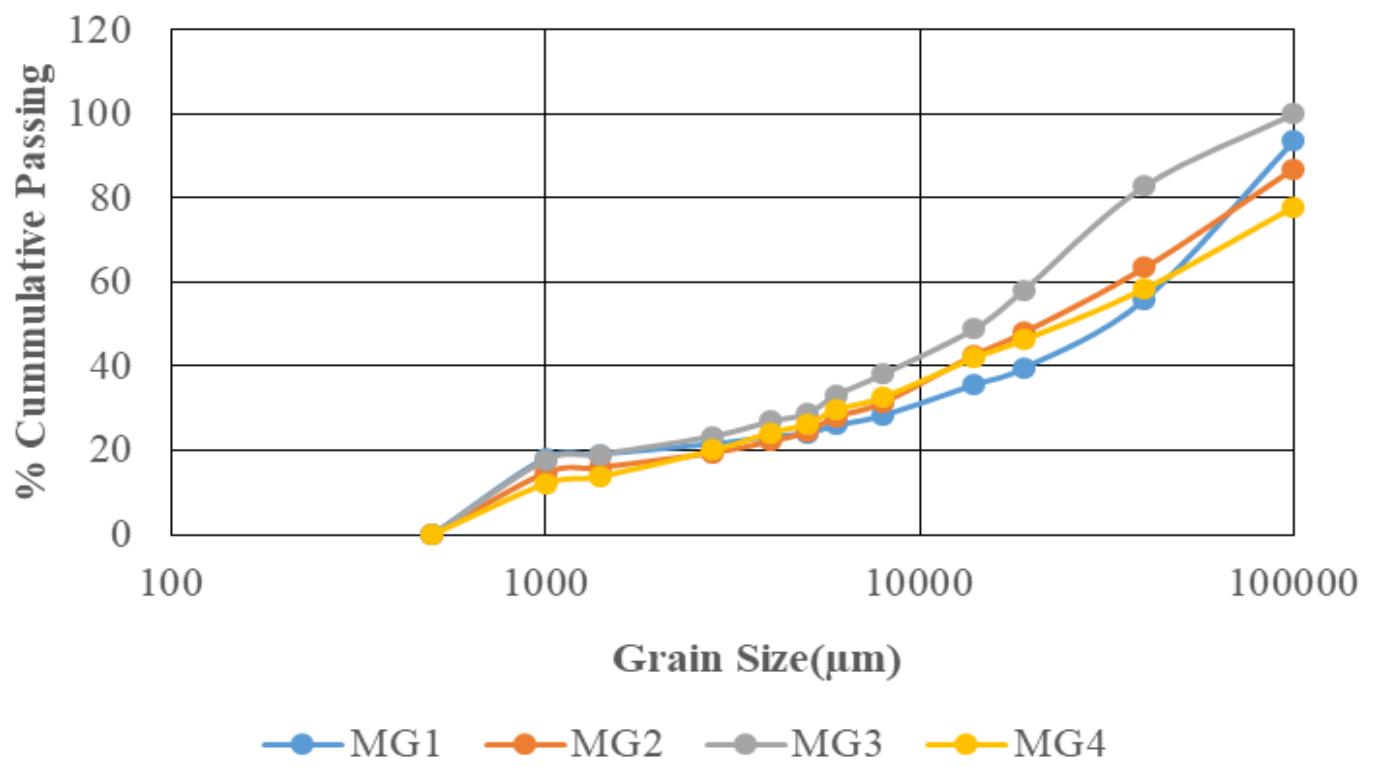

Fig. 1: Particle Size Distribution of MG seams after blasting 


\subsection{Chemical Composition}

The chemical composition analysis indicated that the minerals in the ore are mostly associated with chromium, iron, silica, magnesium, alumium and calcium as main elements within the samples. Their $\%$ by weight present in the ore showed to be uniform throughout all the samples. Previous studies indicated that $\% \mathrm{Cr}_{2} \mathrm{O}_{3}$ in $\mathrm{MG} 1$ ranged at about $42 \%$ which equates to about $28 \%$ by weight of chromium element [5]. In Figure 2, the $\mathrm{Cr} \%$ by weight of the MG1 is $24 \%$ which indicates a slight difference in grade compared to that of MG2, 3 and 4 which is about $21 \%$. However, studies have regarded MG1 as the only economical viable layer to be exploited for chromite extraction within the Middle group seam [5]. This could be the reason why some mines are already exploiting MG2,3 and 4 layers for chromite production [6].

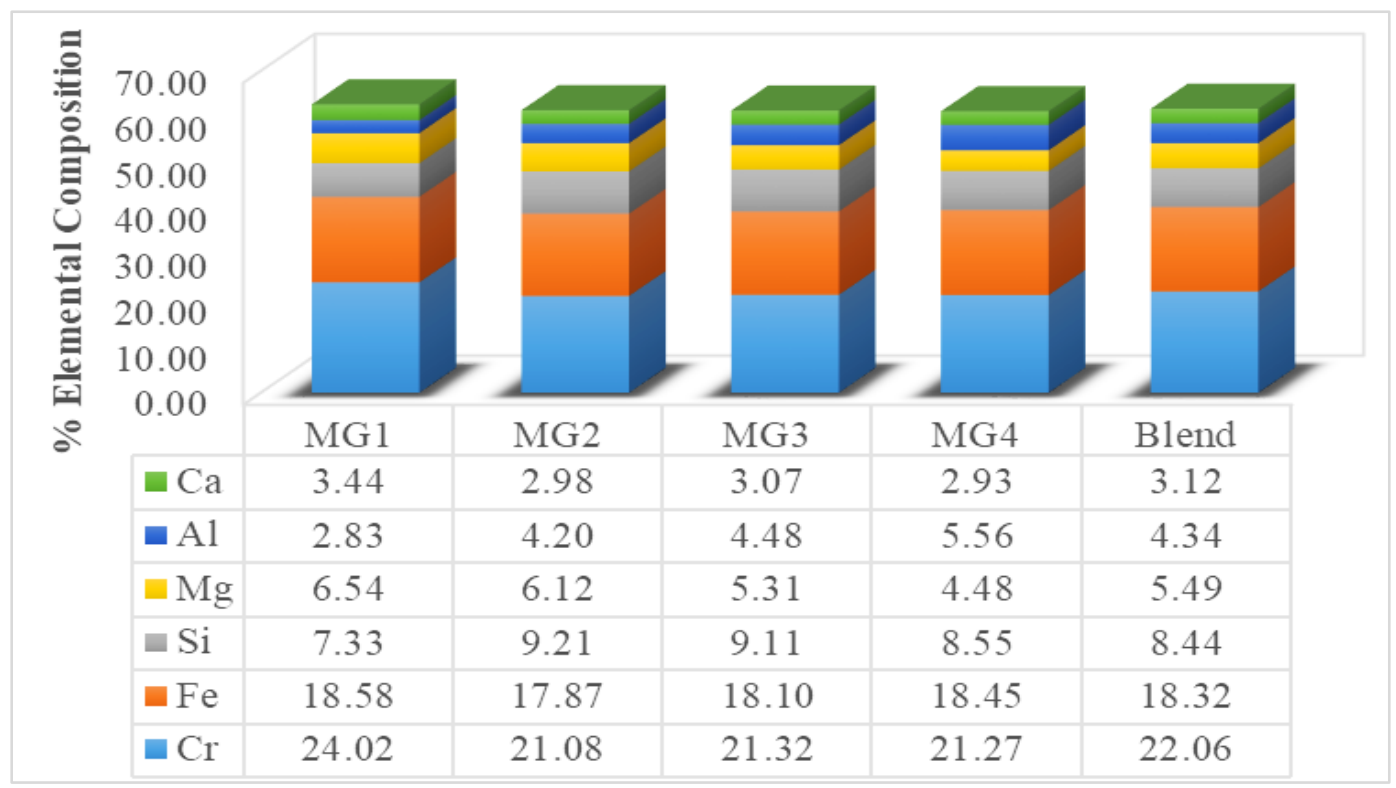

Fig. 2: Elemental Chemical Composition of the MG seams

\subsection{Mineralogical analysis}

The mineralogical analysis in the ore showed that the occurrence of chromite phases in the ore is very similar in all Middle group seam layers as indicated in Figure 3. The six end-member compositions that combine to form chromite are hercynite $\left(\mathrm{FeAl}_{2} \mathrm{O}_{4}\right)$, spinel $\left(\mathrm{MgAl}_{2} \mathrm{O}_{4}\right)$, Fe-chromite $\left(\mathrm{FeCr}_{2} \mathrm{O}_{4}\right)$, magnesiochromite $\left(\mathrm{MgCr}_{2} \mathrm{O}_{4}\right)$, magnetite $\left(\mathrm{Fe}_{3} \mathrm{O}_{4}\right)$, and magnesioferrite $\left(\mathrm{MgFe}_{2} \mathrm{O}_{4}\right)$. Thus, the general formula is $(\mathrm{Mg}, \mathrm{Fe})(\mathrm{Cr}, \mathrm{Al})_{2} \mathrm{O}_{4}$ [1]. Figure 2 showed that the most dominant chromite composition was indicated by the general chromite composition formula $(\mathrm{Mg}, \mathrm{Fe})(\mathrm{Cr}, \mathrm{Al})_{2} \mathrm{O}_{4}$ as obtained from the XRD results and this was also confirmed by XRF chemical composition which showed that the mineral in the sample were associated with $\mathrm{Fe}, \mathrm{Al}, \mathrm{Mg}$ and $\mathrm{Cr}$ elements in an oxidised state. Although the chemical composition in Figure 2 showed high $\%$ by weight of $\mathrm{Fe}$ which is a resemblance of magnetite in the ore, only few phases of magnetite showed some visible peaks in Figure 3, which might be due to magnetite being a low crystalline mineral as compared to chromite itself, not necessarily indicating the low content of magnetite in the ore. 


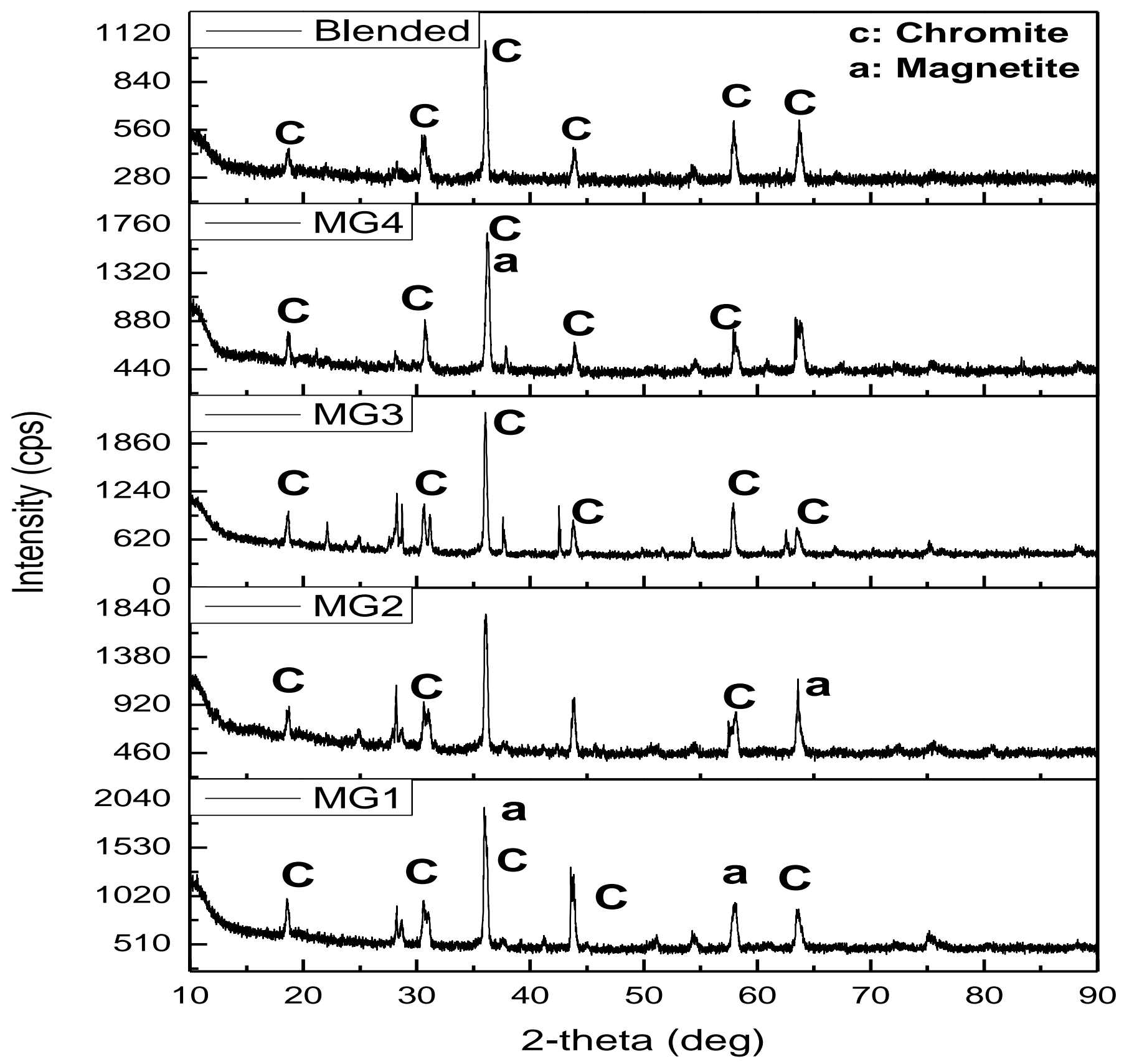

Fig. 3: Mineralogical Phases of the MG seam

\subsection{Elemental analysis and Mineral Distribution in the samples}

Figure 4 shows the sample topography as obtained from SEM and EDS scan. The \% by weight of elements indicated in Figure 4 is a confirmation of the results obtained from chemical composition and mineralogical analysis that were conducted in this study as shown in Figures 2 and 3. Indeed the chromite composition varies and can be associated with elements such as $\mathrm{Mg}, \mathrm{Al}, \mathrm{Fe}$ [1]. Figure 4 shows that minerals are well distributed in the ore 
particularly those of MG2, 3 and 4, however some minerals in MG1 are clustered. Figure 3 also shows that particle size of the grains in the ore ranged between 20 to $418 \mu \mathrm{m}$, with majority being between 150 and $200 \mu \mathrm{m}$ indicating that the ore can be fairly liberated at $80 \mu \mathrm{m}$ to achieve high $\%$ recovery of chromite.
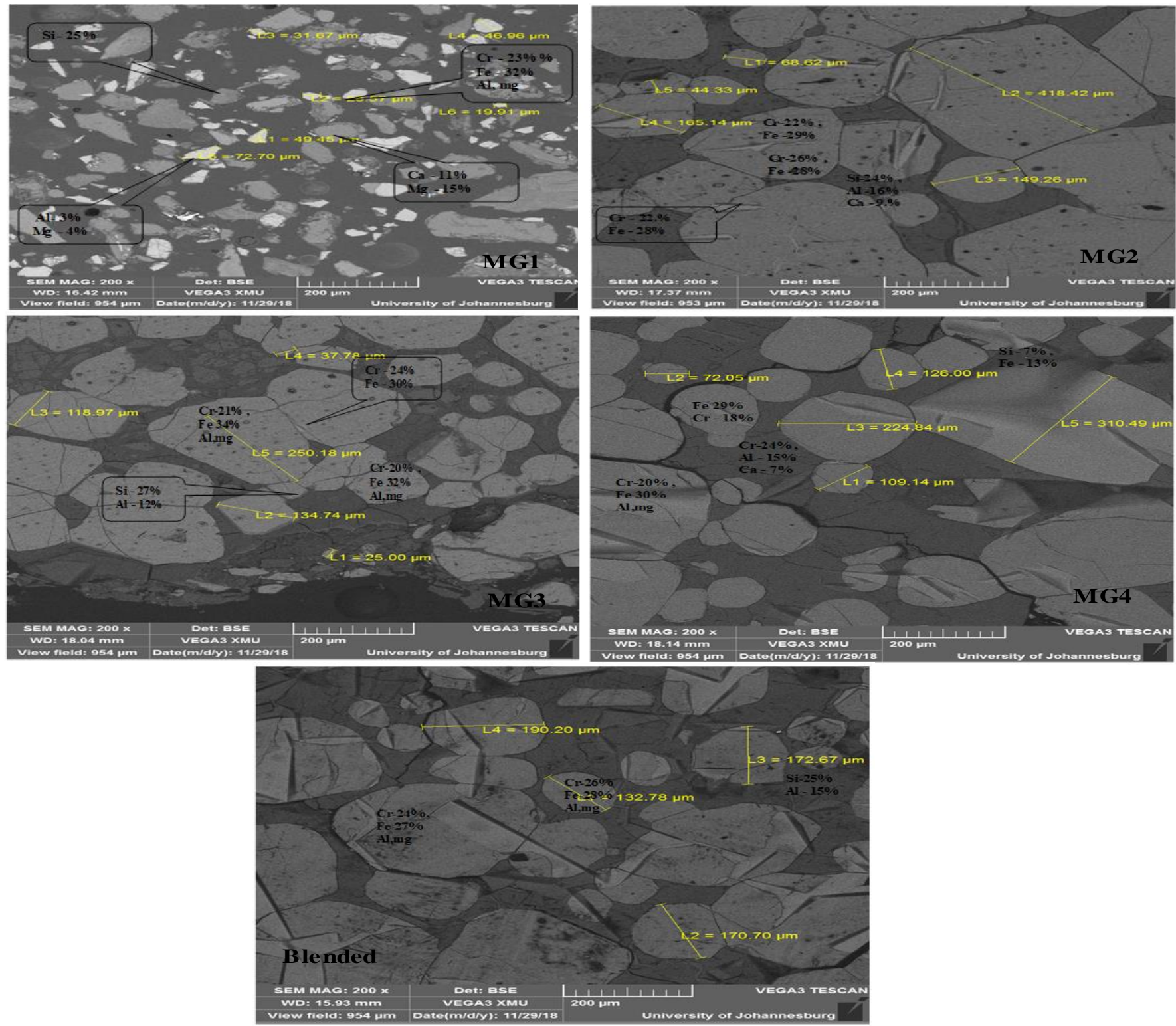

Fig. 4: Micrographs of MG seams and their blend

\section{Conclusion}

From the mineralogical characterisation conducted during this study, it can be concluded that the Middle group seams can be blended together since they all showed very similar physical and chemical characteristic within the samples and they can also be processed separately depending on the availability of the ore especially looking at the thickness of the other layers (MG2, 3 and 4) as compared to the MG1 within the Middle group seam. MG 2, 3 and 4 has coarsely disseminated minerals as compared MG1 and thus finer milling is required when treating MG1 seam. Further tests will be 
carried on mineral liberation (MLA) for $95 \%$ passing the $450 \mu \mathrm{m}$ in order to see if there is any need to further liberate the mineral.

\section{Acknowledgements}

Acknowledgement is given to Thaba Cronimet Mine for the sample provided and the University of Johannesburg for laboratory facilities.

\section{References}

[1] M.Pedrotti, "Chromite : from the mineral to the commodity," 2012.

[2] R. I. Glastonbury, P. J. Beukes, and P. G. Van Zyl, "Comparison of physical properties of oxidative sintered pellets produced with UG2 or metallurgicalgrade South African chromite: A case study," 2015.

[3] S.D.Opoubou-Lando, "Mineralogical characterisation of chromite in the UG2 Reef from Waterval Mine, Western Bushveld : Implications for minerals processing," Cape Town, 2010.

[4] R. P. Schouwstra, E. D. Kinloch, and C. A. Lee, "A Short Geological Review of the Bushveld Complex," Platin. Met. Rev., vol. 44, no. 1, pp. 33-39, 2000.

[5] SSI Holdings, "The South African chrome industry," 2014.

[6] L. Oppermann, M. Junge, S. Schuth, F. Holtz, U. Schwarz-Schampera, and L. Sauheitl, "Mobility and distribution of palladium and platinum in soils above Lower and Middle Group chromitites of the western Bushveld Complex, South Africa," South African J. Geol., vol. 120, no. 4, pp. 511-524, 2017.

[7] S. K. Tripathy, Y. R. Murthy, V. Singh, A. Srinivasulu, A. Ranjan, and P. K. Satija, "Performance optimization of an industrial ball mill for chromite processing," J. South. African Inst. Min. Metall., vol. 117, no. 1, pp. 75-81, 2017.

[8] B. A. Wills and T. Napier-munn, Preface to 7th Edition, no. October. 2006. 